\title{
Childhood obesity in Europe: a growing concern
}

\author{
MBE Livingstone* \\ Northern Ireland Centre for Diet and Health, University of Ulster, Cromore Road, Coleraine, Co. Londonderry, \\ Northern Ireland, BT52 1SA, UK
}

\begin{abstract}
Estimation of the prevalence and secular trends in paediatric obesity in Europe is impeded by methodological problems in the definition of obesity and the paucity of data sets that mirror the demographic, cultural and socioeconomic composition of the European population. The available prevalence data show that paediatric obesity is increasing throughout Europe but the patterns vary with time, age, sex and geographical region. The highest rates of obesity are observed in eastern and southern European countries. Even within countries there may be marked variability in the rates of obesity. It is unclear whether these trends are a simple consequence of an overall increase in fatness in Europe or whether there may be sub-groups of children who, at certain ages, are either particularly susceptible to environmental challenges or are selectively exposed to such challenges. In addition to the general increase in adiposity in European youth, there is also evidence of an increasing degree of obesity, particularly in older children and adolescents. No definite conclusions can be made about the respective contribution of energy intake and physical activity to the increasing prevalence of obesity. Changing demographic and social circumstances are linked to childhood obesity but it is highly unlikely that these interact in similar ways in the genesis of obesity in different individuals and population groups. In conclusion, the limited understanding of the variability in susceptibility to obesity in European youth provides powerful justification for the development of preventive strategies which are population based rather than selectively targeted at high-risk children.
\end{abstract}

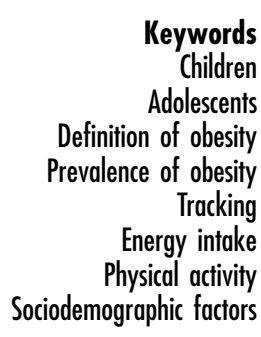

\section{Introduction}

Until recently, paediatric obesity was not recognised as a public health problem in Europe. Obesity in children was uncommon, and, moreover, there was no compelling evidence that childhood obesity tracked into adulthood or had implications for long-term health and longevity. Childhood obesity, particularly during the second decade of life, is now acknowledged to be an increasingly strong predictor of adult obesity, especially for extremely overweight children of obese parents ${ }^{1-4}$. There is also increasing evidence that obesity has deleterious social, economic and health consequences ${ }^{5-9}$. Hence, childhood obesity is now recognised as an important public health issue and this has been further heightened by the increasing prevalence of adult obesity in both developed and developing countries ${ }^{10}$. Consequently, the purpose of this review is to evaluate the existing epidemiological data on the prevalence of overweight and obesity in European youth in relation to secular trends in energy and macronutrient intakes, patterns of physical activity and changes in economic and social variables that may predict childhood obesity.

\section{Defining childhood overweight and obesity}

The definition of overweight and obesity in children and adolescents is less standardised than in adults because natural age-related physiological variations in body composition during childhood make it difficult to distinguish between normal and excessive adiposity. For population screening of obesity, anthropometric measures of height, weight and skinfold thicknesses remain the most feasible and practical methods. However, since skinfold thicknesses and body mass index (BMI) vary in both sensitivity and specificity as indicators of obesity, this represents a major impediment in estimating obesity prevalence and consequently, the results of different studies using different diagnostic criteria can rarely be compared directly ${ }^{11,12}$.

Although skinfold thicknessess provide a direct measure of adipose tissue, they are open to numerous sources 
of both random and systematic error which limits their usefulness for large epidemiological studies and for monitoring changes over time ${ }^{13,14}$. While BMI is now internationally accepted as a reliable and valid measure of adiposity in adults, its application for routine clinical and public health screening of obesity in children and adolescents is more problematic ${ }^{15-17}$. Firstly, since its relationship to body composition is influenced by various factors such as age, sex, ethnicity and maturational stage $^{18,19}$, this necessitates age and sex-dependent reference data for $\mathrm{BMI}^{20-23}$. However, until recently, there has been no widely accepted reference population to facilitate meaningful secular or cross-cultural comparisons between large epidemiological data sets for children.

Secondly, there has been no international consensus about which cut-off to use to define obesity in children. The choice of percentile cut-offs can dramatically affect the number of children screened into the obesity category. For example, estimates of the prevalence of overweight for US children from the third National Health and Nutrition Examination Survey, all based on the same data set, range from 11 to $24 \%$ depending on the cut-offs and the population reference used ${ }^{24}$.

Unlike adults, the evidence to support a classification of childhood obesity based on subsequent morbidity and mortality outcomes is poorly documented and difficult to interpret $^{1}$. A more pragmatic approach, involving the linking of absolute cut-offs for obesity used in adults, e.g. BMI $>25$ (overweight) or $>30$ (obese), with corresponding centiles of BMI in late adolescence, and extrapolating back to childhood has been proposed by the International Obesity Task Force in cooperation with the European Childhood Obesity Group ${ }^{16}$. This has culminated in the first international consensus definition of paediatric obesity based on a reference population drawn from a number of nationally representative data sets ${ }^{25}$.

This initiative will provide a major impetus for assessing the size of the problem of paediatric obesity on an international level, and, provided that the reference BMI norms are fixed in time, will permit secular trends to be monitored. Eventually, it should also be possible to interpret BMI in children from both a physiological and a pathological standpoint.

However, a final problem with BMI is that it is an inferred, and therefore potentially insensitive, measure of fatness in children. The increasing prevalence of obesity in children is more closely associated with marked increases in skinfold defined obesity while BMI defined obesity does not show the same time trends ${ }^{26}$. This may be because the observed increase in body fat has been matched by a corresponding reduction in muscle mass, due to a secular decline in physical activity. Therefore, obesity as defined by BMI could underestimate the scale of the problem unless more sensitive measures of body fatness, such as skinfold thicknesses, are also used to confirm the presence of excess body fat.

\section{Prevalence of paediatric obesity in Europe}

Childhood obesity is now a well recognised problem in Europe. However, at present, intra- and inter- country comparisons of the prevalence in childhood obesity are almost impossible to estimate because of the plethora of definitions and cut-off criteria which are used to define overweight and obesity. Moreover, the monitoring of secular trends in prevalence is severely hampered by the paucity of longitudinal data sets which mirror the ethnic and socio-economic composition of the population.

Longitudinal data sets on nationally representative cohorts of British children born in 1946 and 1958 have been particularly useful for tracking obesity through childhood into adulthood ${ }^{27,28}$. Although the prevalence of obesity among 7-9-year-olds born in 1958 was nearly twice that among those born in 1946, the difference between the two cohorts had almost disappeared by $14-$ 16 years suggesting that the factors pre-disposing to obesity may change with time. More recent mixed longitudinal data show that between 1972 and 1994, triceps skinfold thickness had increased by $8 \%$ and $7 \%$ in English boys and girls respectively and by $10 \%$ and $11 \%$ in Scottish boys and girls respectively ${ }^{29}$. Taken together, these data suggest that the prevalence of obesity in British children is continuing to increase in line with the increased prevalence in British adults ${ }^{30}$.

Unfortunately, the vast majority of prevalence data on paediatric obesity in Europe is cross-sectional in nature and therefore, the development of adiposity in children cannot be tracked and cause-and-effect relationships cannot be established. Moreover, population samples are often small, and even in large samples there is uncertainty about the randomness of the population groups $^{31}$.

Nevertheless, the available prevalence data, no matter how imperfect, show that paediatric obesity is increasing throughout Europe, but the patterns in prevalence vary with time, age, sex and geographical region. Hence, for example, in the Netherlands weight-for-height indices for children remained stable from the 1950's to the 1980 's ${ }^{32}$, but since then there has been an increase in the prevalence of obesity ${ }^{33}$ in line with that observed in Dutch adults over the same period ${ }^{34}$. The trend for rates of obesity to show a marked increase from the 1980's has also been observed in Switzerland ${ }^{35}$ and in France ${ }^{36}$. Moreover, the French data showed that the increase in massive obesity was more important than that of moderate obesity.

The overall pattern suggests that prevalence rates in young children are lower than in adolescents. However, recent data from the UK are of particular concern since they demonstrate an excess of overweight (19\%) and obesity (7\%) in 5-year-olds and highlight the need to initiate effective preventive measures even before children reach school age ${ }^{37}$. Sex differences in obesity 
prevalence are inconsistent, with some studies, for example in Italy $^{38}$, Finland ${ }^{39}$ and Austria ${ }^{40}$ showing the highest prevalence among boys. On the other hand, studies conducted on British ${ }^{28}$, Italian ${ }^{41}$ and Spanish $^{42}$ sub-populations demonstrate the opposite trend. Whether these data reflect real differences or are artefacts due to biased sampling and differences in definition is not known.

Perhaps the most obvious trend from cross-sectional data is the considerable geographical variation in the prevalence of paediatric obesity. The highest rates of obesity are observed in eastern European countries ${ }^{43,44}$ and the southern European countries of Italy, Spain and Greece $^{45}$. In contrast, northern European countries ${ }^{46}$, particularly the Nordic countries ${ }^{47}$, tend to have lower rates overall. Even within countries there may be marked variability in rates of obesity. For example, comparable rates have been found in different areas of northern Italy ${ }^{38}$ but these are lower than those observed in southern Italy ${ }^{48}$. The reasons for these differences are unclear but suggest that, independent of genetic differences, environmental variables are extremely important predictors of obesity which operate in complex ways, both within-andbetween countries.

Clearly the variation in the prevalence of overweight and obesity within-and-between sub-populations confirms the heterogeneous nature of the problem in Europe. While the overall prevalence of obesity is lower than that observed in US youth ${ }^{49}$, nevertheless, there are no grounds for complacency since the rates of obesity in European children look set to increase in the future. In addition to the general increase in adiposity in European youth, there is also evidence of an increasing degree of obesity, particularly in older children and adolescents ${ }^{50}$. This does not bode well since it suggests that the likelihood of obesity persisting from childhood into adulthood will increase into the future ${ }^{2}$.

Whether the trends in adiposity seen in children are a simple consequence of an overall increase in fatness in Europe is not clear. It has been suggested that there may be sub-groups in the population who, at certain ages, are either particularly susceptible to environmental influences, or are selectively exposed to these influences ${ }^{51}$. Obviously, this could have implications for elucidating the causes of obesity as well as for public health strategies for the treatment and prevention of the problem.

\section{Tracking of childhood obesity}

Although obesity in adulthood is associated with increased morbidity and mortality, the long-term health risks associated with childhood overweight are less clear. However, given the relative intransigence of adult obesity there is now common agreement that efforts should be directed at preventing childhood obesity. In theory, identification and targeting preventive efforts at children who are at greatest risk of future obesity is a sound strategy, but this rests on a number of assumptions regarding the tracking of childhood obesity.

Overall, obesity during infancy is not a strong predictor of obesity in adulthood ${ }^{52}$. However, obese children, and especially obese adolescents, are more likely than their normal weight peers to become obese adults ${ }^{1,3}$. The predictive outcome for adult obesity is therefore excellent for 18-year-olds who are obese, good for obese 13-yearolds but only moderate for those less than 13 years of age $^{53}$.

Somewhat surprisingly, however, the majority of obese adults were not obese either in childhood or adolescence $^{1,54}$. It has been estimated that only $20-30 \%$ of the variability in BMI at age 33 years is explained by BMI at age 11 or 16 years ${ }^{2}$. Serdula et al. ${ }^{3}$ have estimated that less than $50 \%$ of adult obesity could be attributed to obesity in childhood. Nevertheless, the fatter the child, the higher the relative risk of becoming a fat adult ${ }^{2}$. The relative risks are also enhanced if one or both parents are obese ${ }^{4}$, and even normal weight children are at a substantially increased risk of becoming obese adults if one or both parents are obese.

The tracking of childhood obesity may also be influenced by the timing of puberty with earlier maturation associated with increased fatness during adulthood $^{55-57}$. However, Power et al. ${ }^{2}$ have demonstrated that while earlier maturation was associated with higher BMI in adulthood, the significance of the association was greatly reduced after adjustment for BMI at 11 and 16 years, suggesting that other important determinants of obesity come into play during adolescence.

Clearly, the earlier childhood obesity can be prevented, the better the likelihood that adult obesity will not occur. However, the existing evidence demonstrates that the prevention of adult obesity cannot rely on the identification and treatment of high risk groups in childhood. Rather they reinforce the arguments in favour of population-focussed approaches to the prevention of obesity.

\section{Trends in energy intake in European children and adolescents}

At present, it is not clear whether obesity develops because of an excess energy intake (EI) relative to energy expenditure (EE), a reduced EE relative to EI, or most likely, a combination of both. While young children appear quite capable of self-regulating their EI under unsupervised conditions ${ }^{58,59}$, this regulatory capacity appears to be easily undermined by a variety of factors including the degree of parental control and attitude towards the child's intake ${ }^{60,61}$. The pressures on children to eat and the opportunities for them to eat may be greater than ever before. Therefore, an intuitively plausible explanation is that passive overconsumption 
of an increasingly varied and palatable food supply is the major variable that predicts body fatness in children.

However, considerable caution needs to be applied when scrutinising EI data sets as a basis for explaining the origins and development of paediatric obesity. Epidemiological studies of food habits and dietary intake in children and adolescents face a number of measurement difficulties which are more-or-less specific to these age groups. Consequently, validation studies using doubly labelled water estimates of EE to assess the accuracy of EI reporting in children indicate that much EI data are prone to bias. A review of these studies shows that the bias does not operate uniformly across age groups and is influenced by the particular method used ${ }^{62}$. Obese adolescents, in particular, may be prone to under-report their usual food intake by a significant margin ${ }^{63}$. Thus, the possibility remains that relative hyperphagia is an important determinant of obesity in children. At the very least, it diminishes the argument that increased energy efficiency is the cause of their adiposity.

Given the caveats about the integrity of much EI data, an extensive review of European dietary intakes of children and adolescents collected over nearly 30 years has shown that there is a wide range in reported $\mathrm{EI}(\mathrm{kJ} / \mathrm{kg}$ per day) within specific age and gender groupings but no obvious secular trends towards decreased or increased $\mathrm{EI}^{31}$. Therefore, it is impossible to conclude if there have been real shifts in EI over time or whether the data reflect unrepresentative study samples and artefacts in dietary survey methodologies.

More recently, attention has focussed on the potential role of the macronutrient composition of the diet in the aetiology of obesity. Limited data suggest that the percentage of total fat energy, independent of total EI and activity level, may contribute to obesity in children ${ }^{64-66}$. Moreover, there is some evidence that this is not a postboc event since children at high risk of obesity, based on parental weight status, had similar total EI but consumed a greater fat energy (\%) and lower carbohydrate energy (\%) than children at low risk of obesity ${ }^{67}$. On the other hand, longitudinal data have shown that high intakes of protein (\% energy) at 2 years can pre-dispose to the development of later obesity via an early adiposity rebound ${ }^{68}$. No other macronutrient was associated with development of adiposity. Nevertheless, parental BMI may yet be a stronger risk factor for childhood obesity than diet composition alone $^{69}$. Given the wide range in the relative proportions of macronutrient energy that have been observed in dietary studies in children ${ }^{31}$, more longitudinal research is clearly required to clarify the contribution of individual dietary components and dietary patterns to childhood obesity.

Despite the wealth of EI data on European children, no definite conclusions can be made about the contribution of food intake to the increasing prevalence of obesity. This dilemma is, at least partially, due to the suspicion that many of these data do not reflect habitual intake. Therefore, in the present state of knowledge, while EI is undoubtedly a variable that predicts adiposity, the magnitude of its impact and its interrelationship with levels of physical activity in the genesis of paediatric obesity remains largely unknown.

\section{Trends in patterns of physical activity in European children and adolescents}

Concurrent with the increasing availability of energy dense foods, Europe has moved to a more sedentary lifestyle and it has been suggested that obesity in adults is now better correlated with indicators of physical activity than with $\mathrm{EI}^{70}$. However, evidence to suggest that current levels of physical activity in children promote overweight is equivocal, methodologically diverse and often crosssectional in nature. Therefore, any such conclusions must be tentative at best.

Nevertheless, a number of trends in patterns of physical activity of European children and adolescents are evident when the available data sets are compared ${ }^{71,72}$. Firstly, children's activity patterns apparently range from very high to very low $^{73}$. Secondly, the overall pattern of physical activity which emerges is consistent and reveals that low levels of activity among children and adolescents are pervasive. Nearly all studies of teenagers indicate that activity levels peak around 13-14 years and then markedly diminish ${ }^{73}$. The largest decrease in physical activity, or best adherence to sedentary activities, seems to occur just before puberty, with a high risk of maintaining this behaviour into adulthood ${ }^{74}$.

Among the reasons cited for habituation to a more sedentary lifestyle during childhood and adolescence are an increase in TV viewing, availability of video and computer games, parental work habits, the increased volume of traffic, parental concern about child abduction and mandatory cut-backs in physical education in schools. Of particular significance for the development of obesity, is the extent to which children spend their leisure time in inactive leisure pursuits such as TV and related pursuits ${ }^{75-78}$.

Thirdly, boys are normally reported to be more active than girls but this discrepancy may be more apparent than real. While boys may participate more in higher intensity activities, the difference between the sexes is greatly reduced when moderate activity alone is compared.

It appears that the wisdom and validity of the common practice of applying adult activity criteria to children's activity patterns needs to be challenged because of their doubtful relevance in the context of evaluating the role of physical activity in the aetiology of childhood obesity. The key to understanding the physical activity/weight gain relationship is more likely to be found in the identification of children who are inactive across a range of social settings, including travel to school and opportunities 
to take part in informal and formalised games. Therefore, instead of dichotomising physical activity it should be treated as a multi-dimensional and continuous variable. In this way the prevalence and value of low-to-moderate intensity activity can be assessed. Such activity may not conform to classical activity guidelines, but it may markedly increase the overall energy expenditure of children if sustained for sufficiently long periods.

In conclusion, the current environment tends to discourage physical activity and children seem to be influenced by the same pressures to be inactive as their parents $^{79}$. The extent to which this reduces their EE has not been fully documented. Consequently, at present, there is no compelling evidence that a sedentary lifestyle is the dominant factor in the aetiology of obesity in European youth. Intuitively, when faced with an increasingly varied, palatable and energy rich diet, it must be exceedingly difficult for the inactive child not to become obese. Unless food intake is limited accordingly, it is inevitable that low levels of physical activity will predispose to obesity, if not during childhood or adolescence, then in adulthood.

These issues can only be properly addressed through the initiation of rigorous, detailed and longitudinal studies on large and representative samples of children using the same valid and precise instruments, a uniform protocol and where appropriate criteria are selected for assessing physical activity as a multi-dimensional and continuous variable. Only then will it be possible to state with confidence that more young people are inactive than active and that their levels of physical activity are a potent risk factor for obesity.

\section{Social factors}

The relationship between social factors and childhood obesity remains equivocal and poorly understood. Physical factors (for example, region, season and population density ${ }^{80}$ ), and social factors (for example, ethnicity $^{81,82}$, family size ${ }^{83}$, excessive television viewing ${ }^{75-78}$, short sleep duration ${ }^{82}$ and rearing conditions ${ }^{84}$ ), have all been associated with adiposity in children and risk of overweight in young adulthood. The role of socioeconomic status has probably been studied the most extensively, but the associations with childhood obesity are inconsistent ${ }^{84-91}$. However, data from the 1946 British birth cohort show that low socioeconomic background in childhood and a high relative weight at age 14 years are associated with higher mean BMI throughout adult life. Moreover, this is only partially confounded by educational attainment and by adult socioeconomic status, suggesting a long-term impact of biological and behavioural processes on $\mathrm{BMI}^{92}$.

In eastern Europe major political changes in the former communist countries have brought about important changes in the social, economic and cultural environments of their inhabitants. In the past, the absence of social differences in the growth of children may have been due to the equalisation of living standards between social groups, suggesting that the health and nutritional status of children from different social strata were compatible. However, economic and social changes currently taking place such as a decrease in birth rates, increase in the number of one-parent families, changes in child rearing practices, increased unemployment, as well as the more obvious lifestyle changes in dietary and activity patterns are, even now, contributing to the increasing prevalence of childhood obesity ${ }^{44}$.

It appears that very few aspects of the social environment are consistently associated with adiposity in children. The most highly significant associations have been with parental BMI and to a lesser extent, children's birth weight ${ }^{81,85,88,93}$. Although the familial aggregation of obesity has a genetic component ${ }^{94}$, it appears that aspects of modern lifestyles now represent the dominant factors which help to account for the observed increase in obesity prevalence over the last several decades. These include decreasing levels of physical activity, child rearing practices, parental attitudes towards diet and physical activity, none of which is easily quantified in population studies. The protective effect of sibling size ${ }^{81,95}$ has yet to be fully explained and at present there is no indication whether larger family size confers permanent protective effects against obesity. The observation that children whose mothers work outside the home and children from one-parent families tend to be at greater risk of obesity are potentially important factors which help to define risk of obesity ${ }^{81}$.

In conclusion, various social factors are clearly linked to childhood obesity but it is highly unlikely that these interact in similar ways in the genesis of obesity in different individuals and population groups. The heterogeneity of socioeconomic conditions throughout Europe and the diversity of factors which underscore them serves to emphasise that continued surveillance of their impact, both positive and negative, on growth and development in European children, now and in the future, is more pertinent than ever.

\section{Conclusion}

Obesity is now a major public health problem in Europe. However, the size of the problem in the paediatric population is obscured by methodological problems of definition and a paucity of repeat cross-sectional and longitudinal data that mirror the economic and social organisation and cultural values of the European population. These data are essential in order to monitor trends in prevalence and to determine what is realistically achievable through public health initiatives. Future research should aim to better understand the causes of the observed differences in prevalence across Europe. At a 
population level this will mean focussing not just on the mechanisms of energy intake and physical activity but also on an evaluation of the environmental forces which, directly or indirectly, are conducive to high levels of overweight and obesity.

Finally, the increasing prevalence of childhood obesity and the relative intransigence of established obesity in adulthood provide convincing evidence that the most effective way to approach the problem is to prevent it in the first place. However, our present limited understanding of variation in susceptibility to obesity is powerful justification for the development of preventive strategies which are population based rather than selectively targeted at high risk children.

\section{References}

1 Power C, Lake JK, Cole TJ. Measurement and long term health risks of child and adolescent fatness. Int. J Obes. Relat. Metab. Disord. 1997; 21: 507-26.

2 Power C, Lake JK, Cole TJ. Body mass index and height from childhood to adulthood in the 1958 British birth cohort. Am. J. Clin. Nutr. 1997; 66: 1094-101.

3 Serdula MK, Ivery D, Coates RJ, Freedman DS, Williamson DF, Byers T. Do obese children become obese adults? A review of the literature. Prev. Med. 1993; 22: 167-77.

4 Whitaker RC, Wright JA, Pepe MS, Seidel KD, Dietz WH. Prediciting obesity in young adulthood from childhood and parental obesity. N. Eng. J. Med. 1997; 337: 869-73.

5 Gortmaker SL, Must A, Perrin JM, Sobol AM, Dietz WH. Social and economic consequences of overweight in adolescence and young adulthood. N. Eng. J. Med. 1993; 329: 1008-12.

6 Sargent JD, Blanchflower DG. Obesity and stature in adolescence and earnings in young adulthood. Arch. Pediatr. Adolesc. Med. 1994; 148: 681-7.

7 DiPietro L, Mossberg HO, Stunkard AJ. A 40-year history of overweight children in Stockholm: life-time overweight, morbidity and mortality. Int. J. Obes. Relat. Metab. Disord. 1994; 18: 585-90.

8 Must A, Jacques PF, Dallal GE, Bajema CJ, Dietz WH. Longterm morbidity and mortality of overweight adolescents: a follow-up of the Harvard Growth Study of 1922 to 1935. N. Eng. J. Med. 1992; 327: 1350-5.

9 Nieto FJ, Szklo M, Comstock GW. Childhood weight and growth rate as predictors of adult mortality. Am. J. Epidemiol. 1992; 136: 201-13.

10 Popkin BM, Doak CM. The obesity epidemic is a worldwide phenomenon. Nutr. Rev. 1998; 56: 106-14.

11 Guillaume M. Defining obesity in childhood: current practice. Am. J. Clin. Nutr. 1999; 70: S126-30.

12 Zimmermann MB, Hess SY, Hurrell RF. A national study of the prevalence of overweight and obesity in 6-12-y-old Swiss children: body mass index, body-weight perceptions and goals. Eur. J. Clin. Nutr. 2000; 54: 568-72.

13 Himes JH. Reliability of anthropometric methods and replicate measurements. Am. J. Phys. Anthropol. 1989; 79: 77-80.

14 Chumlea WC, Guo S, Kuczmarski RJ, Johnson CL, Leahy CK. Reliability for anthropometric measurements in the Hispanic Health and Nutrition Examination Survey (NHANES 19821984). Am. J. Clin. Nutr. 1990; 51: S902-7.

15 Poskitt EM. Defining childhood obesity: the relative body mass index (BMI). Acta Paediatr. 1995; 84: 961-3.

16 Dietz WH, Robinson TN. Use of the body mass index (BMI) as a measure of overweight in children and adolescents. $J$. Paediatr. 1998; 132: 191-3.

17 Prentice AM. Body mass index standards for children are useful for clinicians but not yet for epidemiologists. $B M J$ 1998; 317: 1401-2.

18 Pietrobelli A, Faith MS, Allison DB, Gallagher D, Chiumello G, Heymsfield SB. Body mass index as a measure of adiposity among children and adolescents: a validation study. J. Paediatr. 1998; 132: 204-10.

19 Daniels SR, Khoury PR, Morrison JA. The utility of body mass index as a measure of body fatness in children and adolescents: differences by age and gender. Pediatrics 1997; 99: 804-7.

20 Rolland-Cachera MF, Sempé M, Guilloud-Bataille M, Patois E, Péquignot- Guggenbuhl F, Fautrad V. Adiposity indices in children. Am. J. Clin. Nutr. 1982; 36: 178-84.

21 Cole TJ, Freeman JV, Preece MA. Body mass index reference curves for the UK, 1990. Arch. Dis. Child. 1995; 73: 25-9.

22 Must A, Dallal GE, Dietz WH. Reference data for obesity: 85th and 95th percentiles of body mass index $\left(\mathrm{wt} / \mathrm{ht}^{2}\right)$ and triceps skinfold thickness. Am. J. Clin. Nutr. 1991; 53: 839-46.

23 Lindgren G, Strandell A, Cole T, Healy M, Tanner J. Swedish population reference standards for height, weight and body mass index attained at 6 to 16 years (girls) or 19 years (boys). Acta. Paediatr. 1995; 84: 1019-28.

24 Troiano RP, Flegal KM. Overweight prevalence among youth in the United States: why so many different numbers? Int. J. Obes. Relat. Metab. Disord. 1999; 23: S22-7.

25 Cole TJ, Bellizzi MC, Flegal KM, Dietz WH. Establishing a standard definition for childhood overweight and obesity worldwide: international survey. BMJ 2000; 320: 1240-3.

26 Flegal KM. Defining obesity in children and adolescents: epidemiological approaches. Crit. Rev. Food Sci. Nutr. 1993; 33: 307-12.

27 Stark O, Atkins E, Wolff OH, Douglas JWB. Longitudinal study of obesity in the National Survey of Health and Development. BMJ 1981; 283: 13-7.

28 Peckham CS, Stark O, Simonite V, Wolff OH. Prevalence of obesity in British children born in 1946 and 1958. BMJ 1983; 286: $1237-42$.

29 Hughes JM, Li L, Chinn S, Rona RJ. Trends in growth in England and Scotland 1972 to 1994. Arch. Dis. Child 1997; 76: $182-9$.

30 Seidell JC. Obesity in Europe: scaling an epidemic. Int. J. Obes. Relat. Metab. Disord. 1995; 19: S1-4.

31 Livingstone MBE. Epidemiology of childhood obesity in Europe. Eur. J. Pediatr. 2000; 159: S14-34.

32 Blokstra A, Kromhout D. Trends in obesity in young adults in the Netherlands from 1974 to 1986. Int. J. Obes. Relat. Metab. Disord. 1991; 15: 513-21.

33 Wekke JS-vd, Meulmeester JF, Radder JJ, Hirasing RA, Verloove-Vanhorick SP. PGO-peiling 1992/1993. TNO Preventie en Gezondheid, Leiden, 1994.

34 Seidell JC, Verschuren WMM, Kromhout D. Levels and trends in obesity in the Netherlands. Int. J. Obes. Relat. Metab. Disord. 1995; 19: 924-7.

35 Woringer V, Schutz Y. What is the evolution of the body mass index (BMI) in Swiss children from five to sixteen years, measured one decade apart? Int. J. Obes. Relat. Metab. Disord. 1998; 22: S209.

36 Rolland-Cachera MF, Spyckrelle Y, Deschamps JP. Evolution of pediatric obesity in France. Int. J. Obes. Relat. Metab. Disord. 1992; 16: S5.

37 Reilly JJ, Dorosty AR, Emmett PM. Prevalence of overweight and obesity in British children: cohort study. BMJ 1999; 319: 1039.

38 Maffeis C, Schutz Y, Piccoli R, Gonfiantini E, Pinelli L. Prevalence of obesity in children in north-east Italy. Int. J. Obes. Relat. Metab. Disord. 1993; 17: 287-94.

39 Nuutinen EM, Turtinen J, Pokka T, Kuusela V, Dahlström S, Viikari J, Uhari M, Dahl M, Kaprio EA, Pesonen E, Pietikäinen 
M, Salo MK, Åkerblom HK. Obesity in children, adolescents and young adults. Ann. Med. 1991; 23: 41-6.

40 Elmadfa I, Godina-Zarfl B, König J, Dichtl M, Faist V. Prevalence of overweight and plasma lipids in 7-18 year old Austrian children and adolescents. Int. J. Obes. Relat. Met. Disord. 1993; 17: S35.

41 Maffeis C, Talamini G, Tatò L. Influence of diet, physical activity and parents' obesity on children's adiposity: a fouryear longitudinal study. Int. J. Obes. Relat. Metab. Disord. 1998; 22 : 1-7.

42 Moreno LA, Sarria A, Fleta J, Rodriguez M, Bueno M. Trends in obesity among children in Aragon (Spain) 1985-1995. Int. J. Obes. Relat. Metab. Disord. 1998; 19: S7.

43 Dóber I. The frequency of obesity among schoolchildren of Pécs. (In Hungarian). Népegészségügy. 1987; 68: 90-3.

44 Kromeyer-Hauschild K, Jaeger U, Hoyer H. Prevalence of overweight and obesity among school children in Jena (Germany). Int. J. Obes. Relat. Metab. Disord. 1999; 23: $1143-50$.

45 Amorim Cruz JA. Dietary habits and nutritional status in adolescents over Europe - Southern Europe. Eur. J. Clin. Nutr. 2000; 54: S29-35.

46 Rolland-Cachera MF, Bellisle F, Deheeger M. Nutritional status and food intake in adolescents living in Western Europe. Eur. J. Clin. Nutr. 2000; 54: S41-6.

47 Samuelson G. Dietary habits and nutritional status in adolescents over Europe. An overview of current studies in the Nordic countries. Eur. J. Clin. Nutr. 2000; 54: S21-8.

48 Eposito-Del Puente A, Contaldo F, DeFilippo E, Scalfi L, DiMaio S, Franzese A, Valerio G, Rubino A. High prevalence of overweight in a children population living in Naples (Italy). Int. J. Obes. Relat. Metab. Disord. 1996; 20: 283-6.

49 Flegal KM. The obesity epidemic in children and adults: current evidence and research issues. Med. Sci. Sports Exerc. 1999; 31: S509-S14.

50 Barth N, Ziegler A, Himmelmann GW, Coners H, Wabitsch M, Hennighausen $K$, Mayer $H$, Remschmidt $H$, Schäfer $H$, Hebebrand J. Significant weight gains in a clinical sample of obese children and adolescents between 1985 and 1995. Int. J. Obes. Relat. Metab. Disord. 1997; 21: 122-6.

51 Sørensen TIA, Thomsen BL, Ekstrøm C. Distributional analysis of trends in prevalence of obesity and body mass index among 161,314 Danish boys born 1930 through 1975. Int. J. Obes. Relat. Metab. Disord. 1998; 22: S4.

52 Poskitt EM, Cole TJ. Do fat babies stay fat? BMJ 1977; 1: 7-9.

53 Guo SS, Chumlea WC. Tracking of body mass index in children in relation to overweight in adulthood. Am. J. Clin. Nutr. 1999; 70: S145-8.

54 Braddon FEM, Rodgers B, Wadsworth MEJ, Davies JMC. Onset of obesity in a 36 year birth cohort study. BMJ 1986; 293: 299-303.

55 Garn SM, Lavelle M, Rosenburg KR, Hawthorne VM. Maturational timing as a factor in female fatness and obesity. Am. J. Clin. Nutr. 1986; 43: 879-83.

56 Van Lenthe FJ, Kemper HCG, van Mechelen W. Rapid maturation in adolescence results in greater obesity in adulthood: The Amsterdam Growth and Health Study. Am. J. Clin. Nutr. 1996; 64: 18-24.

57 Van Lenthe FJ, Kemper HCG, van Mechelen W, Post GB, Twisk JWR, Welten DC, Snel J. Biological maturation and the distribution of subcutaneous fat from adolescence into adulthood: The Amsterdam Growth and Health Study. Int. J. Obes. Relat. Metab. Disord. 1996; 20: 121-9.

58 Birch L, Johnson S, Andresen G, Peters J, Schulte M. The variability of young children's energy intake. N. Eng. J. Med. 1991; 24: 232-5.

59 Shea S, Stein A, Basch C, Contento I, Zybert P.. Variability and self-regulation of energy intake in young children in their everyday environment. Pediatrics 1992; 90: 542-6.

60 Lissau I, Breum L, Sorensen TIA. Maternal attitude to sweet eating habits and risk of overweight in offspring: a ten-year prospective population study. Int. J Obes. Relat. Metab. Disord. 1993; 17: 125-9.

61 Birch LL, Fisher JO. Development of eating behaviours among children and adolescents. Pediatrics 1998; 101: 53949.

62 Livingstone MBE, Robson PJ. Measurement of dietary intake in children. Proc. Nut. Soc. 2000; 59: 279-93.

63 Bandini LG, Schoeller DA, Cyr HN, Dietz WH. Validity of reported energy intake in obese and nonobese adolescents. Am. J. Clin. Nutr. 1990; 52: 421-5.

64 Gazzaniga JM, Burns TL. Relationship between diet composition and body fatness, with adjustment for resting energy expenditure and physical activity, in pre-adolescent children. Am. J. Clin. Nutr. 1993; 58: 21-8.

65 Maffeis C, Pinelli L, Schutz Y. Fat intake and adiposity in 8 to 11-year-old obese children. Int.J. Obes. Relat. Metab. Disord. 1996; 20: 170-4.

66 Ortega RM, Requejo AM, Andrés P, López-Sobaler AM, Redondo R, González-Fernández M. Relationship between diet composition and body mass index in a group of Spanish adolescents. Br. J. Nutr. 1995; 74: 765-73.

67 Eck LH, Klesges RC, Hanson CL, Slawson D. Children at familial risk of obesity: an examination of dietary intake, physical activity and weight status. Int. J. Obes. Relat. Metab. Disord. 1992; 16: 71-8.

68 Rolland-Cachera MF, Deheeger M, Akrout M, Bellisle F. Influence of macronutrients on adiposity development: a follow-up study of nutrition and growth from 10 months to 8 years of age. Int. J. Obes. Relat. Metab. Disord. 1995; 19: 5738.

69 Maffeis C, Provera S, Filippi L, Sidoti G, Schena S, Pinelli L, Tatò L. Distribution of food intake as a risk factor for childhood obesity. Int. J. Obes. Relat. Metab. Disord. 2000; 24: 75-80.

70 Prentice AM, Jebb SA. Obesity in Britain: gluttony or sloth? BMJ 1995; 311: 437-9.

71 Molnár D, Livingstone MBE. Physical activity in relation to overweight and obesity in children and adolescents. Eur. J Pediatr. 2000; 159: S45-55.

72 King A, Coles B. The health of Canada's youth: views and behaviours of 11, 13, and 15 year olds from 11 countries. Canada: Ministry of National Health and Welfare, 1992.

73 Riddoch CJ, Boreham CAG. The health-related physical activity of children. Sports Med. 1995; 19: 86-102.

74 Raitakari OT, Porkka KVK, Taimela S, Rasanen L, Viikara JSA. Effect of persistent physical activity and inactivity on coronary risk factors in children and young adults. The Cardiovascular Risk in Young Finns Study. Am. J. Epidemiol. 1994; 140: 195-205.

75 Hillman M. One false move ... an overview of the findings and issues they raise. In: Hillman M, ed. Children, Transport and the Quality of Life. London: Policy Studies Institute, 1993.

76 Gortmaker SL, Must A, Sobol AM, Peterson K, Colditz GA, Dietz WH. Television watching as a cause of increasing obesity among children in the United states, 1986-1990. Arch. Pediatr. Adolesc. Med. 1996; 150: 356-62.

77 Deheeger M, Rolland-Cachera MF, Fonvieille AM. Physical activity and body composition in 10 year old French children: linkage with nutritional intake. Int. J. Obes. Relat. Metab. Disord. 1997; 21: 372-9.

78 Andersen RE, Crespo CJ, Bartlett SJ, Cheskin LJ, Pratt M. Relationship of physical activity and television watching with body weight and level of fatness among children: results from the Third National Health and Nutrition Examination Survey. JAMA 1998; 279: 938-42.

79 Fogelholm M, Nuutinen O, Pasanen M, Myöhänen E, Säätelä T. Parent-child relationship of physical activity patterns and obesity. Int. J. Obes. Relat. Metab. Disord. 1999; 23: 1262-8. 
80 Dietz WH, Gortmaker SL. Factors within the physical environment associated with childhood obesity. Am. J. Clin. Nutr. 1984; 39: 619-24.

81 Duran-Tauleria E, Rona RJ, Chinn S. Factors associated with weight for height and skinfold thickness in British children. $J$. Epidemiol. Community Health 1995; 49: 466-73.

82 Locard E, Mamelle N, Billette A, Miginiac M, Munoz F, Rey S. Risk factors of obesity in a five year old population. Parental versus environmental factors. Int. J. Obes. Relat. Metab. Disord. 1992; 16: 721-9.

83 Keiller SM, Colley JR, Carpenter RG. Obesity in schoolchildren and their parents. Ann. Hum. Biol. 1979; 6: 443-55.

84 Lissau I, Sorensen TIA. Prospective study of the influence of social factors in childhood on risk of overweight in young adulthood. Int.J. Obes. Relat. Metab. Disord. 1992; 16: 169-75.

85 Rona RJ, Chinn S. National study of health and growth: social and family factors and obesity in primary schoolchildren. Ann. Hum. Biol. 1982; 9: 131-45.

86 Rolland-Cachera MF, Bellisle F. No correlation between adiposity and food intake: why are working class children fatter? Am. J. Clin. Nutr. 1986; 44: 779-87.

87 Vuille JC, Mellbin T. Obesity in 10-year-olds: an epidemiologic study. Pediatrics 1979; 64: 564-72.

88 Maffeis C, Micciolo R, Must A, Zaffanello M, Pinelli L. Parental and perinatal factors associated with childhood obesity in north-east Italy. Int. J. Obes. Relat. Metab. Disord. 1994; 18: $301-5$.
89 Wenstrate JA, van Klaveren S, Deurenberg P. Changes in skinfold thicknesses and body mass index in 171 children, initially 1 to 5 years of age: a $51 / 2$-year follow-up study. Int J. Obes. Relat. Metab. Disord. 1986; 10: 313-21.

90 Power C, Moynihan C. Social class and changes in weightfor-height between childhood and early adulthood. Int. J. Obes. Relat. Metab. Disord. 1988; 12: 445-53.

91 De Spiegelaere M, Dramaix M, Hennart P. The influence of socioeconomic status on the incidence and evolution of obesity during early adolescence. Int. J. Obes. Relat. Metab. Disord. 1998; 22: 268-74.

92 Hardy R, Wadsworth M, Kuh D. The influence of childhood weight and socioeconomic status on change in adult body mass index in a British national birth cohort. Int. J. Obes. Relat. Metab. Disord. 2000; 24: 725-34.

93 Garn S, Bailey S, Cole P, Higgins ITT. Evidence for the social inheritance of obesity in childhood and adolescence. In: Gedda L, Parisi P, eds. Auxology: buman growth in health and disorder. London: Academic Press, 1978.

94 Stunkard AJ, Sorensen TIA, Hanis C, Teasdale TW, Chakraborty R, Schull WJ, Schülsinger F. . An adoption study of human obesity. N. Eng. J. Med. 1986; 314: 193-8.

95 Ravelli GP, Belmont L. Obesity in nineteen-year-old men: family size and birth order associations. Am. J. Epidemiol. 1979; 109: 66-70. 